\title{
Reduction of Timing Jitter by Clock Recovery based on an Optical Phase-Locked Loop
}

Zibar, Darko; Mørk, Jesper; Oxenløwe, Leif Katsuo; Clausen, Anders; Jeppesen, Palle

Published in:

Proceeding of IEEE Conference on Laser Electro Optics

Link to article, DOI:

10.1109/CLEO.2006.4627778

Publication date:

2006

Document Version

Publisher's PDF, also known as Version of record

Link back to DTU Orbit

Citation (APA):

Zibar, D., Mørk, J., Oxenløwe, L. K., Clausen, A., \& Jeppesen, P. (2006). Reduction of Timing Jitter by Clock Recovery based on an Optical Phase-Locked Loop. In Proceeding of IEEE Conference on Laser Electro Optics (pp. 1-2). IEEE. https://doi.org/10.1109/CLEO.2006.4627778

\section{General rights}

Copyright and moral rights for the publications made accessible in the public portal are retained by the authors and/or other copyright owners and it is a condition of accessing publications that users recognise and abide by the legal requirements associated with these rights.

- Users may download and print one copy of any publication from the public portal for the purpose of private study or research.

- You may not further distribute the material or use it for any profit-making activity or commercial gain

- You may freely distribute the URL identifying the publication in the public portal 


\title{
Reduction of Timing Jitter by Clock Recovery based on an Optical Phase-Locked Loop
}

\author{
Darko Zibar, Jesper Mørk, Leif K. Oxenløwe, Anders T. Clausen and Palle Jeppesen \\ COM DTU, Technical University of Denmark, Kgs. Lyngby, DK-2800, Denmark \\ dz@com.dtu.dk \\ Abstract \\ We numerically investigate the phase noise requirements for combined electrical/optical local \\ oscillators in a PLL-based clock recovery. Suggestions for reducing the timing jitter are given. \\ OCIS codes: (060.2330) Fiber optics communications; (060.4510) Optical communications
}

\section{Introduction}

Optical 3R regeneration is considered to be a key technology for bit rates of $40 \mathrm{~Gb} / \mathrm{s}$ and above. For $3 R$ regeneration, clock signal extraction from a distorted data signal is needed and the extracted clock signal must exhibit lower timing jitter than the degraded data signal. Clock recovery has been performed by various techniques, e.g. by a Self-Pulsating DFB Laser (SPL), a Mode-Locked Laser (MLL) and an optical PLL (OPLL), see e.g. [1]. In order for a recovered clock signal to have less jitter than the input signal, the jitter of the free-running local oscillator must be less than that of the input signal. An advantage of using an OPLL-based clock recovery is that one has access to a recovered electrical and optical clock signal. In this paper, we investigate the timing jitter requirements for the electrical and optical local clock sources, in order to obtain a recovered clock signal with less timing jitter than the degraded input signal. This is done by using a newly developed detailed numerical model. Furthermore, the dependence of the recovered clock's signal timing jitter on the laser's characteristic knee frequency (jitter transfer) is investigated numerically.

2. Model set-up

The model set-up of the OPLL, shown in Fig. 1, is based on the experimental realization presented in [2].
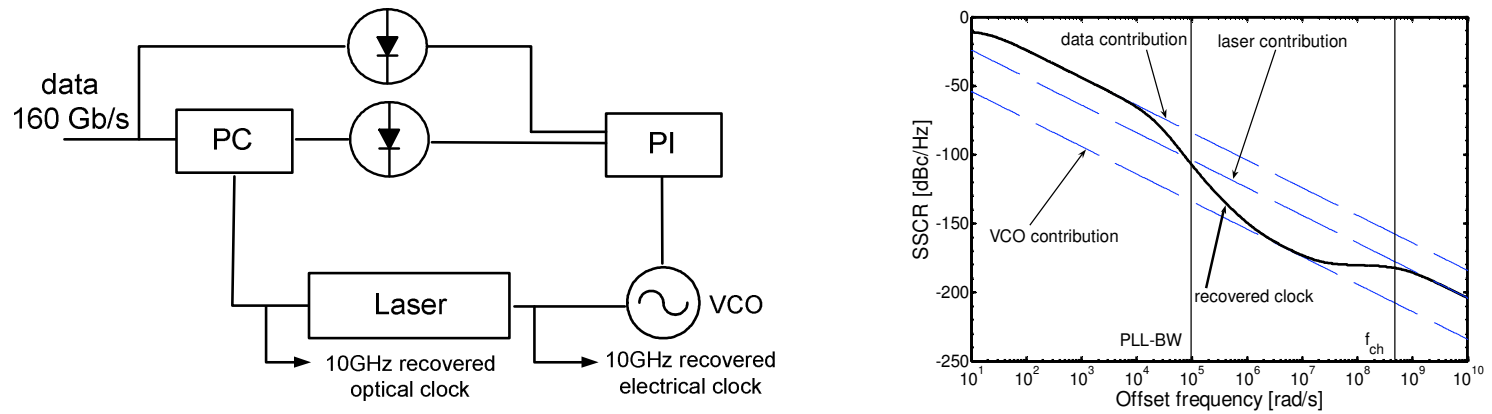

Fig. 1. (a) Schematic set-up of OPLL based CR. (b) SSCR of the recovered optical clock signal. Input, VCO and laser jitter: $800 \mathrm{fs}, 500 f$, $50 \mathrm{fs}$.

The Phase Comparator (PC) mixes the optical high-speed data signal (e.g. $160 \mathrm{~Gb} / \mathrm{s}$ ) with the locally generated optical clock signal at the base rate (e.g. $10 \mathrm{GHz})$ producing an error signal. In practice, ultra-fast non-linear processes like FWM in SOAs can be used to achieve the mixing, see e.g. [2]. The error signal is a slowly varying signal proportional to the phase and frequency difference between the local optical clock and the data signal. The balanced photodetection (BW $100 \mathrm{MHz}$ ) provides a subtraction of the DC level from the error signal, which results in a bipolar error signal. The signal is then low pass filtered through a Proportional Integrator (PI) filter and fed back to the VCO, which controls the laser. The largest contributions to the timing jitter of the extracted clock signal will come from the phase noise associated with the input data signal, the VCO and the laser. For simplicity, we are therefore going to assume that the loop components do not contribute with any noise. The PLL is modelled in the small-signal regime by an Ornstein-Uhlenbeck process [3]. The phase noise of the data, the VCO and the laser are modelled as Brownian motion stochastic processes filtered by the laser transfer function, with a characteristic knee frequency of $\mathrm{f}_{\mathrm{ch}}$. The characteristic knee frequency denotes the bandwidth around the laser's centre frequency within which jitter is transferred from the VCO to the pulse source [4].

\section{Results}

Fig. 1(b) shows that within the PLL bandwidth, the Single Sideband to Carrier Ratio (SSCR) of the recovered optical clock signal follows the SSCR of the input data signal. $f_{\mathrm{ch}}$ determines the frequency at which the SSCR of 

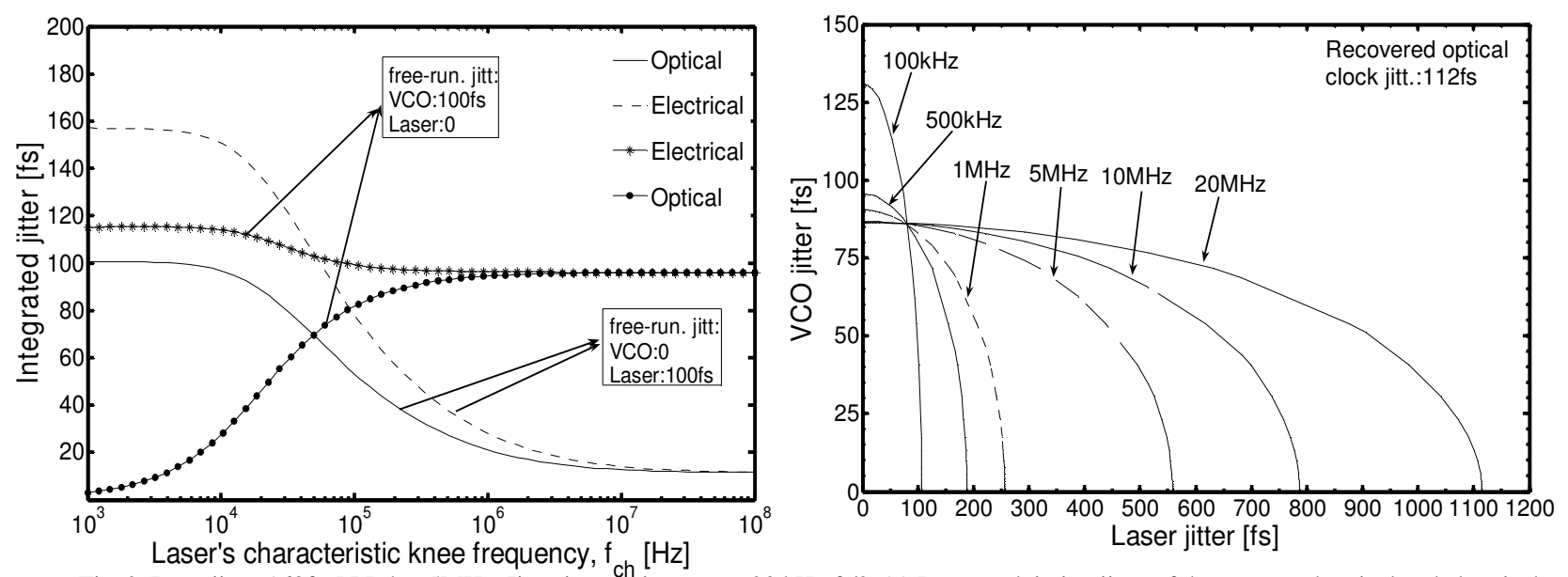

Fig. 2. Input jitter:160fs. PLL-bw:5MHz. Jitter integration range: $20 \mathrm{kHz}-\mathrm{f}_{0} / 2$. (a) Integrated timing jitter of the recovered optical and electrical clock signal as a function of the laser's characteristic knee frequency. (b) Contour curves for a constant timing jitter of $112 \mathrm{fs}$ of the recovered optical clock as a function of the VCO's and laser's free-running jitter. $\mathrm{f}_{\mathrm{ch}}$ is varied from $100 \mathrm{kHz}-20 \mathrm{MHz}$.

the optical clock signal couples to the SSCR of the free-running laser. In Fig. 2, the integrated timing jitter of the recovered optical and electrical clock signal is computed as a function of $f_{c h}$. When the jitter of the free-running laser is $100 \mathrm{fs}$ and the corresponding jitter of the VCO is set to be negligible, the timing jitter of the recovered optical clock signal reduces as $\mathrm{f}_{\mathrm{ch}}$ is increased. This is because the clock signal jitter is dominated by the phase noise of the local oscillators above the PLL-bandwidth. As the characteristic knee frequency of the laser is increased, the SSCR of the optical clock signal is coupled to the VCO in a larger bandwidth, and as the VCO has zero jitter in the considered case, the overall optical clock signal has lower jitter [5], see Fig. 1(b). When the jitter associated with the free-running laser is negligible and the VCO free-running jitter is $100 \mathrm{fs}$ it is observed that the timing jitter of the recovered optical clock signal decreases as $f_{c h}$ is reduced. By keeping $f_{c h}$ low, the VCO jitter is not transferred to the clean laser signal. For the extracted electrical clock signal the integrated timing jitter reduces as the laser's characteristic knee frequency is increased. Furthermore, the recovered optical clock signal exhibits less timing jitter than the electrical clock signal in the range: $1 \mathrm{kHz}-2 \mathrm{MHz}$. Fig. 2(b) depicts the contour curves for a constant timing jitter of 112 fs ( $~ 30 \%$ jitter reduction compared to the input) of the recovered optical clock signal as a function of the free-running jitter of the $\mathrm{VCO}$ and the laser. The input data signal jitter is $160 \mathrm{fs}$ and $\mathrm{f}_{\mathrm{ch}}$ is varied from $100 \mathrm{kHz}$ to $20 \mathrm{MHz}$. Fig. 2(b) illustrates that as $\mathrm{f}_{\mathrm{ch}}$ is increased the timing jitter requirement for the laser becomes more relaxed as the integrated clock signal jitter becomes less affected by the laser jitter. The VCO jitter requirements become more stringent as the laser's characteristic knee frequency, $\mathrm{f}_{\mathrm{ch}}$, is increased. However, this is insignificant when $\mathrm{f}_{\mathrm{ch}}$ is above $500 \mathrm{kHz}$.

\section{Conclusion}

We have numerically investigated the influence of electrical and optical local oscillators on the timing jitter of the recovered clock signal. Timing jitter requirements for the laser can be significantly relaxed by a large laser characteristic knee frequency using a low-noise VCO. In general, if the laser has more jitter than the VCO it is preferable to have a large laser characteristic knee frequency and if the laser has less jitter than the VCO it is preferable to have small laser characteristic knee frequency.

\section{References}

[1] J. Lasri et al, "Ultralow timing jitter 40Gb/s clock recovery using self-starting optoelectronic oscillator”, IEEE Photonics Technology

Letters,vol. 16, no. 1, January 2004

[2] L. K. Oxenløwe et al., "Pre-scaled clock recovery with compact semiconductor devices for ultra high-speed OTDM systems", in Proceedings of IEEE ECOC 2004, Stockholm Sweden, paper We3.5.2, 2004

[3] A. Mehrotra, "Noise analysis of phase-locked loops", IEEE Transactions on Circuits and Systems - I: Fundamental Theory and Applications, vol. 49, no. 9, September 2002

[4] Braun M. A. et al, "Universality of mode-locked jitter performance”, IEEE Photonics Technology Letters,vol. 14, no. 8, August 2002

[5] D. Zibar et al., "Timing jitter analysis of clock recovery circuits based on an optoelectronic phase-locked loop", in Proceedings

of IEEE CLEO 2005, Baltimore, Maryland, USA, paper CMZ4, 2005 